\title{
Stem cells in prostate cancer: treating the root of the problem
}

\author{
Renea A Taylor, Roxanne Toivanen and Gail P Risbridger
}

Prostate and Breast Cancer Research Group, Department of Anatomy and Developmental Biology, Monash University, Clayton, Victoria 3800, Australia

(Correspondence should be addressed to G P Risbridger; Email: gail.risbridger@monash.edu)

\begin{abstract}
Prostate cancer is a hormone-dependent, epithelial-derived tumor, resulting from uncontrolled growth of genetically unstable transformed cells. Stem cells are therapeutic targets for prostate cancer, but as disease progression occurs over decades, the imperative is to identify and target the cancer-repopulating cell (CRC) that maintains malignant clones. In order to achieve this goal, we will review the current knowledge of three specific types of cells, their origins, and their differentiation potential. The first is the normal stem cell, the second is the cancer cell of origin, and the third is the CRC. Specifically, we review three proposed models of stem cell differentiation in normal tissues, including linear, bidirectional, and independent lineages. We consider evidence of the cancer cell of origin arising from both basal and luminal cells. Finally, we discuss the limited data available on the identity and characterization of CRCs in localized and castrate-resistant prostate cancer, which is where we believe the focus of future research efforts should be directed. Ultimately, understanding the intrinsic or extrinsic influences that dictate the behavior of these unique cells will be instrumental in facilitating the development of new therapeutic targets for prostate cancer.
\end{abstract}

Endocrine-Related Cancer (2010) 17 R273-R285

\section{Introduction}

Prostate cancer is a major cause of morbidity and mortality in men around the world, being the most common solid tumor. In America, $\sim 6$ out of every 50 men over the age of 50 will be diagnosed with prostate cancer in his lifetime. In 2006 alone, the American Cancer Society reported 234460 men diagnosed and 27350 deaths from prostate cancer (Penson \& Chan 2007). These statistics underscore the significance of this cancer and predict the significant health burden on our aging population. Prostate cancer is treated by surgery or radiation when confined to the organ at diagnosis, and as it is an androgen-dependent malignancy, androgen deprivation therapy (ADT) is used to control the disease, if disease relapse occurs. However, cancer cells can adapt to androgen-depleted conditions and patients inevitably progress from hormone sensitive to develop castrate-resistant prostate cancer (CRPC). Carcinogenesis occurs in the prostatic epithelium, and results in sequential disruption of coordinated reciprocal signaling between stroma and epithelium (Hayward et al. 1997).
In this review, we consider stem cells as cellular targets for prostate cancer therapies. To avoid confusion throughout our review, we propose to discuss prostatic stem cells during disease progression focusing on three specific types of cells, their origins, and their differentiation potential. The first is the normal stem cell, the second is the cancer cell of origin, and the third is the cancer-repopulating cell (CRC). Conventionally, stem cells are defined by their ability to self-renew and differentiate into progeny. In normal tissues, stem cells are the epithelial populations with full lineage potential that are proven to regenerate tissue-specific progeny (Potten \& Loeffler 1990, Watt \& Hogan 2000). We also consider the cancer cell of origin. This is not necessarily a stem cell in normal tissue, but may also be a progenitor, which is susceptible to malignant transformation. Thirdly, we will discuss the CRC, defined as a population of biologically distinct tumor cells possessing stem cell properties. These cells have the ability to self-renew, repopulate the tumor after chemotherapy, and play a role in subsequent metastasis (Bonnet \& Dick 1997, 
Reya et al. 2001, Wicha et al. 2006). Other terms which have been used for CRCs are 'cancer stem cells' or 'cancer-initiating cells', but this terminology does not distinguish adequately between a cancer cell of origin and a CRC. Thus, for the purposes of this review, we will avoid these terms and instead use stem cell, cancer cell of origin, and CRC, as defined earlier.

Of all these stem cell types, the most appropriate therapeutic target is the CRC. However, there is a need to know the relationship between stem cells in normal tissue, cancer cell(s) of origin, and CRCs. Herein, we present three proposed models of stem cell differentiation in normal tissues, including linear, bidirectional, and independent lineages. We present evidence for cancer cell(s) of origin from progenitors of both basal and luminal cells. Finally, we discuss the limited data available on the identity and characterization of CRCs in localized and advanced prostate cancer, which we believe is where future research efforts should be directed.

\section{Prostatic stem cells in normal tissue}

\section{Classification of prostatic epithelial cell types in normal tissue}

In order to discuss the role of stem cells in normal tissues, it is important to identify the key cell types of the normal epithelium. Prostatic epithelium is composed of multiple differentiated cell types, including basal, luminal (secretory), and neuroendocrine cells. In addition, an intermediate cell type that shares properties of both luminal and basal cells is described (De Marzo et al. 1998, Wang et al. 2001, Uzgare et al. 2004, Signoretti \& Loda 2007). Luminal secretory cells make up the majority of the epithelial layer and because they express androgen receptors (ARs), they can respond directly to androgens by simulating production and secretion of prostatic proteins, such as prostate-specific antigen (PSA) and prostatic acid phosphatase (Coffey 1992, Hudson 2004, Kurita et al. 2004). The basal cells exist as one or two layers attached to the basement membrane below the luminal cells (McNeal 1981, 1988, Kurita et al. 2004, Heer et al. 2007) and can be distinguished from other prostatic cells by their morphology, ranging from small, flattened cells with condensed chromatin and small amounts of cytoplasm to cuboidal-like cells with an increased cytoplasm and more open-appearing chromatin. In the human prostate, basal cells form a continuous layer, whereas in other species they are more scattered in appearance. This is reflected in the ratio of basal:luminal cells, which is $\sim 1: 1$ in human prostate, whereas the average ratio in other species, such as mouse, dog, monkey, and rat, is $\sim 1: 7$ (El-Alfy et al. 2000). Basal cells usually have low AR expression and exclusively express p63 (a homolog of the tumor suppressor gene p53; Signoretti et al. 2000, Signoretti \& Loda 2007). Neuroendocrine cells are the least studied epithelial cell population and are believed to regulate prostate growth and development through endocrine-paracrine actions (Bostwick \& Dundore 1997). They are rare cells located in the luminal layer of the epithelium, together with the secretory cells they tend to be more abundant in the major ducts and more sparsely present in acinar tissue (Abrahamsson 1999).

Prostatic epithelial cells are identified by their morphological appearance, location, and also distinct patterns of marker expression. Basal cells express cytokeratins (CKs) 5 and CK14, but not CK8 or CK18. Luminal cells are devoid of basal cell markers, expressing CK8 and CK18, but not CK5 or CK14. Intermediate cells express CKs of both basal and luminal cells (CKs 5, 14, 8, and 18; De Marzo et al. 1998, Wang et al. 2001, Uzgare et al. 2004, Signoretti \& Loda 2007; see Fig. 1). Throughout this review, these cell types will be denoted as basal $\left(\mathrm{CK} 5^{+} 8^{-}\right)$, intermediate $\left(\mathrm{CK} 5^{+} 8^{+}\right)$, and luminal $\left(\mathrm{CK} 5^{-} 8^{+}\right)$cells.

\section{Identity and characterization of prostatic stem cells in normal tissue}

Although the prostate is a slow growing organ with limited cycles of cell proliferation and apoptosis, prostatic stem cells exist within the epithelium, which are capable of regenerating the adult organ (DeKlerk \& Coffey 1978). Although stem cells in the normal prostate are not a direct target for cancer therapies, fundamental understanding of their identity and characteristics provide an imperative basis to our understanding of cancer cell(s) of origin and CRCs. There is a significant controversy in the field with regard to these cells based on conflicting data, leading to multiple proposed differentiation hierarchies. We review three generally accepted models of stem cell differentiation in normal tissue, including linear, bidirectional, and independent lineages. The true stem cell hierarchy(s) is likely to involve a combination of all models, but more data are required to resolve this issue.

\section{Linear differentiation model}

Adult prostatic stem cells were originally postulated to reside within the basal cell compartment because of the ability of the prostatic epithelium to regress and regenerate from residual basal cells after repeated 


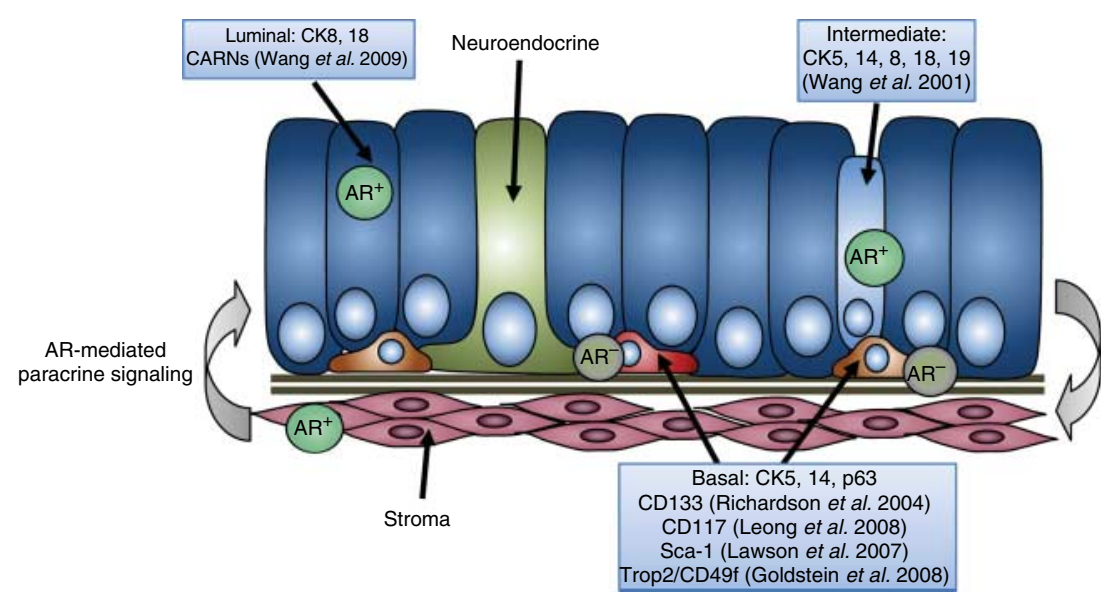

Figure 1 Cellular identity of prostate stem cells. The prostate in composed of stromal and epithelial compartments that communicate through reciprocal communication. The epithelium consists of several identifiable cell types, including basal, intermediate, luminal, and neuroendocrine cells that have defining cytokeratin (CK) profiles and differing androgen receptor (AR) expression. Putative stem cells are identified in the $\mathrm{AR}^{-}$basal compartment, based on sorting for cell surface markers including CD133, CD117, Sca-1, Trop2, and CD49f, or in the luminal compartment where $\mathrm{AR}^{+}$castrate-resistant Nkx3-1-expressing cells (CARN) reside.

cycles of castration and testosterone replacement (DeKlerk \& Coffey 1978, Kyprianou \& Isaacs 1988, Montpetit et al. 1988, Verhagen et al. 1988). Biologically, basal cells exhibit many stem cell characteristics, including their relatively undifferentiated state, high proliferative capacity, protection from apoptosis, and a long life span (Potten \& Loeffler 1990, Bonkhoff et al. 1994, De Marzo et al. 1998, Foster et al. 2002). A linear hierarchical model of stem cell differentiation in prostatic epithelia is defined by Isaacs \& Coffey (1989), where stem cells within the basal layer give rise to one stem cell copy (self-renewal) and one multipotent progenitor cell (or transient amplifying cell), by asymmetric cell division. During expansion, progenitor cells translocate toward the luminal cell layer and gain either exocrine or neuroendocrine characteristics through an intermediate cell phenotype (Bonkhoff 1996, De Marzo et al. 1998, van Leenders \& Schalken 2001; Fig. 2A). This linear model is similar to other regenerative tissues such as bone marrow, skin, intestinal tract, and squamous epithelium, as demonstrated by studies that use cell surface markers to isolate enriched populations that are identified as putative stem cells based on their regenerative functionality using in vitro and in vivo assays.

The ability to isolate and study stem cells in human prostate tissues based on cell surface markers is limited by the availability of healthy tissue from an undiseased human prostate gland. Therefore, most findings are established and extrapolated from the use of mouse models. Several cell surface markers are reported to identify prostate stem cells in the basal cell compartment, including stem cell antigen-1 (Sca-1, also known as Ly6a), ALDH, CD133 (Prom1), Trop-2, and CD44 (Liu et al. 1997, Burger et al. 2005, Xin et al. 2005, Lawson et al. 2007, Tsujimura et al. 2007, Goldstein et al. 2008, Yao et al. 2010). However, many nonstem cells in the mouse prostate also express these markers. Most recently, Leong et al. (2008) identified CD117 (c-kit, stem cell factor receptor) as a new marker of a rare adult mouse prostatic stem cell population that fulfills all the functional characteristics of stem cells including self-renewal and full differentiation potential. Used in combination with other stem cell markers, single cells defined by the phenotype $\mathrm{Lin}^{-} \mathrm{Sca}^{-}{ }^{+} \mathrm{CD} 133{ }^{+} \mathrm{CD} 44^{+} \mathrm{CD} 117^{+}$regenerate prostatic epithelium that consists of all epithelial cell types and produces secretions in vivo. Long-term self-renewal capacity is evident by their ability to regenerate tissue after serial isolation and subsequent transplantation (Leong et al. 2008). CD117 expression is predominantly localized to the proximal region of the mouse prostate and is upregulated after castrationinduced prostate involution, consistent with prostate stem cell identity and function. $\mathrm{CD} 117^{+}$cells are predominantly basal $\left(\mathrm{CK} 14^{+}\right)$in the mouse and exclusively basal $\left({\left.\mathrm{p} 63^{+}\right)}^{+}\right.$in the human (Leong et al. 2008). This landmark paper describes single basal cells in the adult mouse prostate with multipotent, self-renewal capacity, defined by CD117 expression.

Although mouse models provide sufficient information relating to stem cells in normal tissues, translation to human tissues is inadequate. The majority of literature in human prostate is based on an enriched population of $\alpha_{2} \beta_{1}$ integrin $\left(\alpha_{2} \beta_{1}^{\text {hi }}\right)$ $\mathrm{CD} 44^{+} \mathrm{CD} 133^{+}$cells described by the Maitland 
A
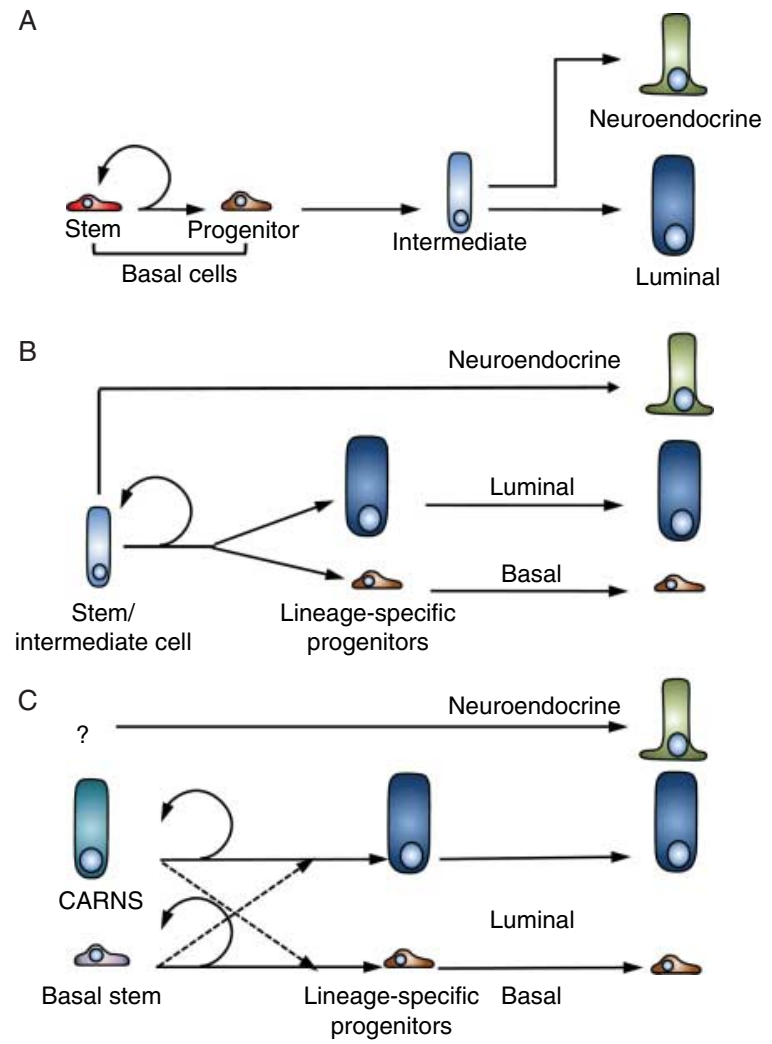

Figure 2 Models of prostate stem cell hierarchies: based on functional and ontological studies, several different models of differentiation hierarchy for putative prostatic stem cells are proposed. (A) Linear hierarchical arrangement: prostatic stem cells are postulated to reside in the basal cell layer, based on functional studies using markers including CD117, Sca-1, Trop2, CD49f, and CD133. In this model, basal cells self-renew, give rise to progenitor (or transit amplifying cells; also basal phenotype), followed by intermediate cells and then terminally differentiated luminal or neuroendocrine cells in a linear manner. (B) Nonlinear hierarchical arrangement: a second differentiation model is proposed where a common stem cell gives rise to a lineage-specific progenitors, which then give rise to distinct cell lineages of basal, luminal, and neuroendocrine cells. This model is most similar to that proven for mammary stem cell differentiation. In the prostate, epithelial cells with an intermediate phenotype (i.e co-expressing markers of both basal and luminal cells) are proposed to house this common stem cell. (C) Independent arrangement: most recently, the identification of luminal stem cells (CARN; based on Nkx3-1 expression) was demonstrated using expression of $N k \times 3-1$ in castrate-resistant prostate tissues. This discovery raises the possibility of multiple stem cells within the epithelium that independently gives rise to distinct cell lineages including basal, luminal, and neuroendocrine cells. This model does not exclude the possibility that basal and/or luminal stem cells can be multipotent and generate the opposing lineage as well.

Laboratory (Collins et al. 2001, Richardson et al. 2004). This subpopulation of cells isolated from benign human prostate tissues show unique ability to form prostatic-like acini over their negative counterparts when xenografted in vivo (Richardson et al. 2004), suggesting $\mathrm{CD}_{133^{+}}$cells represent enriched prostatic stem cells, whereas $\mathrm{CD} 133^{-}$cells are an enriched transient amplifying/progenitor population. Although limited, some studies use other markers in addition to CD133 to identify human prostatic stem cells, including Trop2 and CD49f, which are enriched in the basal epithelium of human prostate and show greater sphere-forming activity in vitro (Goldstein et al. 2008). Testing of other markers, including CD117, is warranted, as this marker is also expressed in basal cells of benign human prostate (Leong et al. 2008), although translation of other cell surface markers from mouse to human, such as Sca-1, is problematic because expression is not shared between species. Therefore, we currently have more functional evidence for prostatic stem cells in murine tissues than in human tissues.

\section{Bidirectional differentiation model}

The linear hierarchical model where $\mathrm{CK} 5^{+} 8^{-}$basal cells contain the prostatic stem cell population was reviewed by Wang et al. (2001), who comprehensively mapped the pattern of CK expression in mouse and human tissues during development and in the mature prostate (Wang et al. 2001). They postulated that if prostatic stem cells are located in the urogenital sinus epithelium (UGE), then $\mathrm{CK} 5^{+} 8^{-}$basal cells would be enriched in UGE tissues. However, they only detected $\mathrm{CK} 5^{+} 8^{+}$intermediate cells (that expressed the full complement of CKs) in human, mouse, and rat fetal UGE (as well as mature tissues), and therefore proposed that $\mathrm{CK} 5^{+} 8^{+}$intermediate cells, and not $\mathrm{CK} 5^{+} 8^{-}$basal cells, house the prostatic stem cell population that can divergently give rise to basal or luminal cells in a bidirectional manner (Wang et al. 2001; Fig. 2B).

A second piece of data that questions the basal cell origin of prostate stem cells, is the generation of prostatic tissue from the p63-knockout mouse (Kurita et al. 2004). Grafting and rescue studies using this mouse model resulted in mature epithelium (containing all prostatic cell lineages) that undergoes several rounds of serial regression/regeneration in the absence of basal cells (Kurita et al. 2004). Again, these data fail to support the suggestion that $\mathrm{CK} 5^{+} 8^{-}$basal cells are the 'only' source of prostatic stem cells, and indicate the possible existence of a distinct multipotent stem cell in the intermediate or luminal cell population.

The bidirectional model of prostatic stem cells is similar to the stem cell model of the mouse mammary gland, where the normal stem/progenitor cell hierarchy 
is better documented. Mammary stem cells (MaSCs) give rise to a common (bi-potent) progenitor, which generates distinct luminal and myoepithelial progenitors that develop into independent lines of differentiated cell types, including ducal, alveolar, and myoepithelial cells (Visvader 2009). MaSCs are enriched by sorting for $\mathrm{Lin}^{-} \mathrm{CD} 24^{+} \mathrm{CD} 29^{-}$, and single-cell assays demonstrate their functionality in vitro and in vivo (Shackleton et al. 2006).

\section{Independent lineage model}

Both hierarchical models, including linear and bidirectional pathways, postulate that stem cells are confined to a single-cell type, either basal or intermediate cell. However, most recently new data suggest that the prostate gland may also contain stem cells in the luminal compartment, based on the identification of a rare cell that is castrate resistant. Shen's Laboratory used the expression of the $N k x 3-1$ homeobox gene to indentify a luminal cell population that displays stem/progenitor properties during prostate regeneration (Wang et al. 2009). By using genetic lineage marking, rare luminal cells that express $N k x 3-1$ in the absence of testicular androgens (castrate-resistant Nkx3-1-expressing cells, CARNs) are shown to be bi-potent and maintain the capacity to self-renew in vivo; single-cell transplantation assays show that CARNs can reconstitute prostate ducts in renal grafts (Wang et al. 2009). Functional assays of Nkx3-1 mutant mice in serial prostate regeneration suggest that $N k x 3-1$ is required for stem cell maintenance. As these data do not concur with previous reports of basal cells as stem cells, Wang et al. proposed that CARNs may be an additional stem cell, such that prostatic stem cells can reside in both basal and luminal compartments, thereby giving rise to their own cell types, rather than being derived from a common stem cell. This model does not exclude the possibility that basal and/or luminal stem cells can be multipotent and generate the opposing lineage as well (Fig. 2C).

Collectively, we present data to implicate prostatic stem cells in basal, intermediate, and luminal cells, and their respective models of differentiation remain speculative. In our opinion, the proposed models may not be mutually exclusive, and all three of the pathways may be active during some stage of development (or disease progression). We also consider that it is possible that cells displaying stem cell properties occur in more than one cell type and that the characteristics that define a stem cell can be switched on or off depending on their response to extrinsic or intrinsic regulatory factors.

\section{Cancer cell of origin}

Although we cannot absolutely define stem cells in normal prostatic epithelium, there is an emerging interest in identifying the cancer cell of origin. We have defined the cancer cell of origin as the epithelial cells in normal prostate glands that are susceptible to malignant transformation and therefore capable of initiating tumorigenesis. In general, cancer can arise from normal stem cells that undergo malignant transformation, as these cells exist for the life of the patient, thereby having greater chance of harboring genetic insults leading to tumorigenesis (Reya et al. 2001). Alternatively, transient amplifying or progenitor cells can give rise to malignancy, in a process where more rapidly proliferating cells harbor genetic insults leading to tumor formation (Signoretti \& Loda 2007). Without a clear definition of stem cells in normal prostate (and considering there may be more than one), it is difficult to determine whether the cancer cell of origin in prostate cancer is a stem cell, multipotent progenitor/transient amplifying cell, or a more differentiated progeny. Nonetheless, evidence exists that the cellular origin can include both basal and luminal (CARN) cells.

Although putative stem/progenitor cells can reside in $\mathrm{CK} 5^{+} 8^{-}$basal cells, a diagnostic feature of human prostate cancer is the loss of basal cells (Humphrey 2007, Grisanzio \& Signoretti 2008). Therefore, prostate cancer can potentially arise from oncogenic transformation of $\mathrm{CK}^{+} 8^{-}$basal cells resulting in rapid differentiation to a luminal phenotype, or alternatively from stem or multipotent progenitor cells within the $\mathrm{CK} 5^{+} 8^{+}$intermediate or $\mathrm{CK} 5^{-} 8^{+}$ luminal populations where stem cells or CARNs are proposed to reside. This is certainly true in the wellcharacterized mouse mammary epithelium, where aberrant proliferation of the luminal progenitor population, rather than MaSCs, is shown to be the target for transformation in BRAC1-associated tumors (Lim et al. 2009). In addition, the multiple subclassification of breast cancer types can be associated with tumors arising from different epithelial cells in the hierarchical tree, suggesting that multiple cell types have the capacity to become tumorigenic (Visvader 2009). This may be similar in prostate cancer, but our understanding is not so advanced as in breast cancer and based on the occurrence of luminal or neuroendocrine tumors, subclassifications of tumor linked to the specific cell type of origin are unknown.

There is evidence to implicate both basal and luminal populations containing cancer cell(s) of origin in prostate cancer. First, multiple lines of evidence 
demonstrate initiation of prostate cancer from luminal (and possibly intermediate) cells, based on targeted gene disruption by Cre-recombinase under the control of the probasin (either probasin or $\mathrm{ARR}_{2}$ /probasin) or PSA promoters that show luminal-specific expression. The genetic targets vary widely, including Pten tumor suppressor gene (Ma et al. 2005), myc (Ellwood-Yen et al. 2003), and Nkx3-1 (Iwata et al. 2010), which result in tumorigenesis under luminalspecific expression. Targeted deletion of Pten in CARNs results in rapid carcinoma formation after androgen-mediated regeneration (Wang et al. 2009). These data indicate that luminal cells, including the CARNs as luminal stem cells, represent a population that is an efficient target for oncogenic transformation in prostate cancer. Together, these findings indicate that luminal cells represent a potential cancer cell of origin.

Alternatively, a body of work by the Witte Laboratory provides evidence to suggest that basal cells can initiate preneoplastic and cancerous lesions. For example, loss of PTEN negatively regulates $p 63^{+}$ prostatic basal cell proliferation without blocking differentiation, resulting in an expansion of a prostate stem/progenitor-like subpopulation, using defined cell lineage markers including $\mathrm{Sca}-1^{+}, \mathrm{Bcl}-2^{+}$, and CD49f ${ }^{\text {hi }}$ cells (Wang et al. 2006, Mulholland et al. 2009, Lawson et al. 2010). Most recently, this group introduced a series of genetic alterations into prospectively identified populations of mouse basal stem and luminal cells and showed basal cells, but not luminal cells, are efficient targets for prostate cancer initiation (Lawson et al. 2010). Whether there are two independent cancer cells of origin in the prostate remains unknown.

When considering translation of this information to human tissues, again the data are limited. Studies in human prostate cancer indicate that $\mathrm{CD}_{133}{ }^{+}$is a common marker of cells with stem-cell-like properties in both nonmalignant and malignant tissues (Richardson et al. 2004, Collins et al. 2005). This led to the assumption that $\mathrm{CD} 133^{+}$stem cells in normal tissues are the cancer cell of origin in prostate cancer. However, an opposing view was proposed by Vander Griend et al. (2008), who proposed that prostate cancer is derived from $\mathrm{AR}^{+}$cells, which are unlikely to be stem cells in normal tissues, and tumor cells subsequently acquire 'stem-like activity' by gaining expression of $\mathrm{CD} 133^{+}$. Similar to breast cancer, there may be more than one cellular origin of human prostate cancer, which may correlate with tumor phenotype, but is yet to be formally documented.

\section{Cancer-repopulating cells}

In cancer, a population of biologically distinct tumor cells possessing stem cell properties are defined as CRCs. These cells have proliferative potential to maintain tumor bulk and resist chemotherapy in order to repopulate the tumor and cause metastasis after cancer treatment (Reya et al. 2001). In general, CRCs are proposed to conform to one of two proposed models of differentiation. Originally, a hierarchical model of CRC differentiation suggests that $\mathrm{CRCs}$ and their progenitors give rise to more differentiated cells with less regenerative potential (Reya et al. 2001, Dick 2009). This model is based on fractionation of tumor cells using cell surface markers to isolate rare subsets of tumors cells from the brain, blood, and colon that display exclusive tumor regenerating potential in colony-forming assays and in vivo transplantations in immunedeficient mice (Bonnet \& Dick 1997, O’Brien et al. 2007). However, xenotransplantation studies using fractionated cell populations are complicated because of the tumor cell interactions with the microenvironment, mediated by both soluble and membrane-bound factors (Hanahan \& Weinberg 2000). The rarity of human tumor cells that survive transplantation may simply reflect the cells that can most readily adapt to growth in a foreign (mouse) milieu. This is confirmed by the variation in results with advancing use of different immune compromised mouse hosts, such as NOD-SCID-IL2R $\gamma^{\text {null }}$ (NSG) mice (Kelly et al. 2007). In melanoma, the original frequency of xenotransplantation of human metastatic melanoma cells is reported to be 1 in 1090000 when transplanted into NOD/SCID mice (Schatton et al. 2008), whereas recent data by Quintana et al. (2008) showed that $\sim 1$ in 4 (25\%) unselected tumor cells are capable of tumor formation in NSG mice, demonstrating the crucial reliance of optimal transplantation conditions in determining tumorigenic potential in vivo. Therefore, tumorigenic assays for prostate CRCs must ensure the survival of human cancer cells in the model being used, so that any read out of repopulating potential is related only to its biological properties, and not to limitations of the assay. Based on the repopulating capacity of a greater proportion of the tumor in NSG mice, an alternative CRC model is proposed, where all cancer cells are homogeneous (equal), and that random influences change the behavior of individual cells, including intrinsic factors such as transcription factors or signaling pathways and/or extrinsic factors such as host factors, microenvironment, and immune 
response. This stochastic model, based on clonal evolution, suggests that CRCs are derived from populations of cancer cells that confer a selective growth advantage and are not restricted to a particular cell type within the tumor (Campbell \& Polyak 2007). Unlike the hierarchical model, clonal evolution is a nonstructured multistaged process, where different clones can obtain this advantage throughout the cancer progression, resulting in intratumoral variation (Shackleton et al. 2009). This alternate model also provides a plausible explanation for the biological and functional heterogeneity detected in tumors.

\section{CRCs in prostate cancer}

In prostate cancer, the identification and characterization of CRCs (or cells with selective growth advantage) may be different in androgen-dependent disease compared to castrate-resistant disease. Therefore, in this section, we will consider localized and CRPC separately (Fig. 3). Localized tumors are composed of a heterogeneous mix of cell types, and the differentiation capacity and hierarchical relationship between these cell types have not been defined, particularly in human tissues. Less is known about the cellular components of CRPC tumors. As mice are extremely resistant to prostate cancer initiation, models of carcinogenesis in rodents are often artificial and show minimal resemblance to the actual biology in human prostate. Therefore, the majority of studies that attempt to identity and characterize CRCs in prostate cancer use human tissues.

\section{CRCs in localized prostate cancer}

The identity of CRCs in prostate cancer, defined by the functional ability to undergo self-renewal and differentiate the entire progeny of the tumor mass, is unclear. The putative stem cell marker, CD133 ${ }^{+}$, isolates prostate cancer cells with stem-cell-like properties, including a significant capacity for self-renewal and regeneration of phenotypically mixed populations of nonclonogenic cells that express differentiated cell products, including AR and PSA in vitro (Collins et al. 2005). This population represents $\sim 0.1 \%$ of cells in prostatic tumors, without correlation to Gleason grade. These data, conducted using in vitro assays, represent the only attempt to prospectively isolate CRCs in human prostate cancer. Unlike other tumor types, including melanoma, leukemia, brain, or colon, functional identification of CRCs using transplantation and limiting dilution assays in vivo has not been conducted. This is an important area of research if we are to consider CRCs as cellular or molecular targets for therapy.

\section{CRCs in CRPC}

Without identifying or characterizing CRCs in localized prostate cancer, it is difficult to determine their role in progression to metastasis or the development of CRPC. Regardless, it is evident that there is a subpopulation of prostate cancer cells that are resistant to current therapeutics, particularly ADT, which is a front line therapy for advanced disease. When tumors relapse after ADT, presumably because of the repopulating potential of a subset of cancer cells, treatment consists of symptom management and at
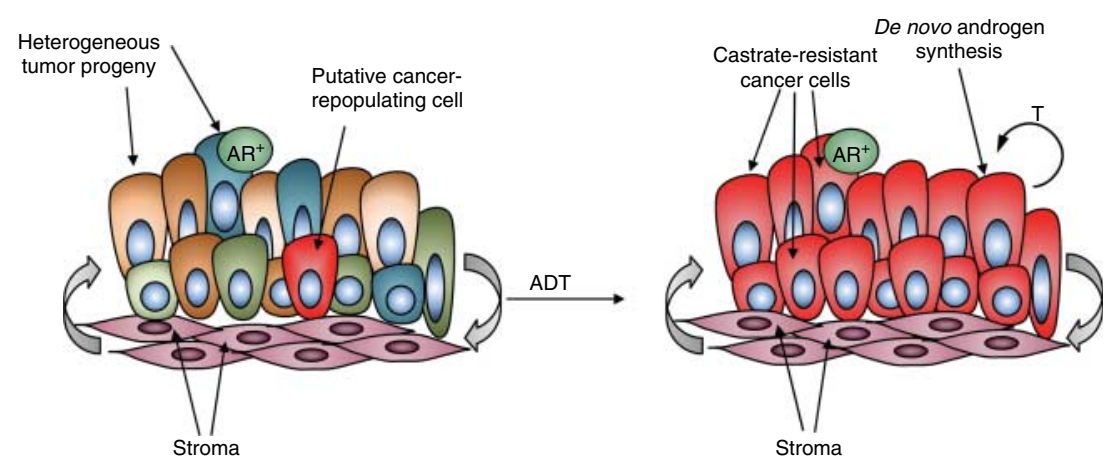

Figure 3 Prostate cancer-repopulating cells. In localized, androgen-dependent prostate cancer (left panel), cancer-repopulating cells (CRCs) are proposed to be a rare subpopulation distinguishable from the bulk of the tumor by their ability to survive treatment and regenerate tumor mass. The identity of these cells is less defined than that of in other solid tumors, but CD133 is postulated to enrich prostate cancer CRCs. The expression status of AR in human CD133 ${ }^{+}$CRCs remains under debate, but the tumor bulk is $\mathrm{AR}^{+}$and is therefore androgen dependent. After failed front line therapies (i.e. radical prostatectomy or radiotherapy), patients commonly undergo androgen deprivation therapy (ADT). Recurrent disease after this treatment leads to castrate-resistant prostate cancer. In these tumors, the residual cancer cells gain the ability to adapt the androgen-depleted environment and synthesize their own androgens de novo in order to mediate and maintain cancer cell survival and growth. It is unknown whether the adaptive ability is common to all cancer cells or restricted to CRCs from the earlier stage tumor. 
times toxic chemotherapy although patients invariably succumb to the disease.

In CRPC, tumor cells adapt to the low-androgen environment and continue to mediate androgen signaling by AR overexpression, amplification, mutation, and altered coregulator interactions (Scher et al. 2004), but also by gaining the ability to synthesize sufficient androgens de novo to activate AR pathways and allow the growth of cancer despite negligible amounts of androgens in the circulation (Locke et al. 2008; Fig. 3). Whether all cells or only a selected population are capable of renewing and repopulating based on their ability to make androgens or express the AR (potentially as a result of clonal selection) is unknown. Identifying the subpopulation responsible for de novo steroid genesis would give invaluable insight into advanced prostate cancer biology, and create novel targets for castrateresistant disease.

\section{Molecular targets for CRCs in prostate cancer}

In an attempt to identify molecular factors that can specifically target stem cells in normal tissue or CRCs in prostate cancer, two genetic profiling studies are reported on benign and malignant prostatic CD133 ${ }^{+}$ epithelial cells isolated from human specimens. In benign prostatic hyperplasia, $\mathrm{CD} 133^{+}$cells expressed genes relating to undifferentiated cells such as TDGF1, and targets of the Wnt and Hedgehog developmental pathways, whereas $\mathrm{CD}_{133^{-}}$cells showed upregulated proliferation and metabolism genes, related more specifically to a transient amplifying population (Shepherd et al. 2008). In cancer, specifically CRPC, CD133 ${ }^{+}$cells displayed a more transient amplifying population phenotype with increased metabolic activity and proliferation, possibly explaining the transition from a relatively quiescent state to an active growing tumor phenotype, perhaps reflecting that CD133 isolates biologically distinct cells from benign compared to malignant tissues (Shepherd et al. 2008). Similar array analysis on cultured samples of localized primary human prostate cancer reveals $\mathrm{CD} 133^{+}$cells display a proinflammatory phenotype as $\mathrm{NF} \kappa \beta$ expression is increased reflecting the immune responsiveness of $\mathrm{CD} 133^{+}$cells (Birnie et al. 2008). With further investigation and discovery of the identity of CRCs, the molecular targets within these cells will become evident and may lead to clinical applications for men with prostate cancer.

\section{The role of endocrine hormones in regulation of stem cell types}

All three stem cells (normal stem cells, cancer cell of origin, and CRCs) reside in a niche environment, predominantly composed of prostatic stroma that plays a major role in dictating stem cell fate. Extensive studies on prostate gland development show that epithelial differentiation is induced and maintained by stromal signaling, specifically mediated by hormonal and paracrine signaling mechanisms (Cunha \& Donjacour 1989); direct androgen binding to epithelial ARs is not required for epithelial differentiation (Chung \& Cunha 1983, Takeda et al. 1990), but is essential for the induction and maintenance of secretory activity (Donjacour \& Cunha 1993, Cunha 1994). The potent effect of stromal induction and essential requirement of androgens for prostate development are reflected by the fact that other tissue types differentiate into prostate when grown with inductive prostatic mesenchyme in male host mice that provide an androgen-rich endocrine environment (Taylor et al. 2009). Of note, almost all the in vivo studies testing the growth and/or tumor potential of subpopulations of cells, co-transplanted inductive prostatic stroma (Lawson et al. 2007, 2010, Goldstein et al. 2008, Leong et al. 2008, Mulholland et al. 2009, Lukacs et al. 2010). Without the stromal-mediated AR signaling, it is unlikely that the fractionated cell populations would survive and/or proliferate in vivo, regardless of their AR status, as stromal-epithelial signaling is integral to prostatic differentiation.

In prostate cancer, the stromal niche or microenvironment also plays a critical role in regulating differentiation of CRCs, potentially by altered endocrine and/or paracrine signaling. Prostatic tumor stroma has a distinct phenotype that is known to facilitate tumorigenesis (Taylor \& Risbridger 2008), whereby carcinoma-associated fibroblasts can promote tumor progression and contribute to metastasis (Olumi et al. 1999). Some of the key regulators of this activity are members of the transforming growth factor $\beta$ superfamily and/or specific chemokines and cytokines that promote malignant transformation of the epithelium (Joesting et al. 2005, Ao et al. 2007). Although AR expression is high in developing nonmalignant prostatic stroma, AR expression in prostate cancer stroma is often low to detect (Henshall et al. 2001, Ricciardelli et al. 2005, Wikstrom et al. 2009). This provides an imbalance in the stromal-epithelial steroid signaling in cancer compared to normal tissues, and this altered microenvironment significantly affects the growth and differentiation signals received by the 
epithelium, especially CRCs, although this interaction remains relatively unexplored.

Similar to the prostate gland, the mammary gland is a hormone-dependent organ susceptible to tumorigenesis. The recent prospective isolation of MaSCs (in addition to committed progenitor and mature luminal cells) from murine tissues shows a receptor-negative phenotype for ER $\alpha, \mathrm{PR}$, and ErbB2 (Asselin-Labat et al. 2006, Shackleton et al. 2006). Regardless of this, MaSCs are highly responsive to steroid hormone signaling; ovariectomy markedly diminished MaSC number and outgrowth potential in vivo, whereas estrogen and progesterone increased MaSC activity in mice (Asselin-Labat et al. 2010). The same is likely to be true for prostatic stem cells, but has not been tested.

Without a clearly defined stem cell population in normal or cancerous prostate tissues, the steroid receptor status and responsiveness to androgens remain undefined. Prostatic basal cells demonstrate low levels of AR but are androgen responsive, as demonstrated by regeneration of the prostatic tissue from basal cells during re-administration of testosterone after castration in rodents (Montpetit et al. 1988, Verhagen et al. 1988, Bonkhoff \& Remberger 1993, De Marzo et al. 1998). Basal cells that show stem cell properties, based on Sca- $1^{+}$cells in mouse and $\mathrm{CD} 133^{+}$cells in human, also express low or no AR expression compared to their negative counterparts (Wang et al. 2006, Heer et al. 2007). The AR expression and sensitivity to androgens is characterized in the linear hierarchical model where $\mathrm{CK} 5{ }^{+} 8^{-}$basal cells (containing stem cells and transient amplifying or progenitor cells) are $\mathrm{AR}^{-}$, whereas $\mathrm{CK} 5^{+} 8^{+}$intermediate and $\mathrm{CK} 5^{-} 8^{+}$ luminal cells are $\mathrm{AR}^{+}$(De Marzo et al. 1998, Uzgare et al. 2004). In keeping with known expression patterns of luminal prostatic epithelia, CARNs (luminal stem cells) always express AR (Wang et al. 2009). In human prostate cancer, there is a debate over the AR status of $\mathrm{CD}_{133^{+}}$cells, as they were originally reported to be $\mathrm{AR}^{-}$(Richardson et al. 2004), but conflicting data suggest that $\mathrm{CD}_{133}{ }^{+}$cells responsible for tumor propagation and progression are $\mathrm{AR}^{+}$and therefore are direct targets for androgen stimulation (Vander Griend et al. 2008). As the use of cell surface markers to isolate fractionated cell populations usually enriches for cells of mixed phenotypes, the function and repopulating potential of $\mathrm{AR}^{+}$and/or $\mathrm{AR}^{-}$cells remains unknown. It is possible with the advancing identification of prostatic stem cells that a pure $\mathrm{AR}^{-}$ population will be identified in nonmalignant tissues, similar to the MaSC, but the AR status in localized or CRPC tumors may vary between cancer types. Additionally, the expression of estrogen receptors
(ERs), $\mathrm{ER} \alpha$ and $\mathrm{ER} \beta$ is unknown, but is of interest based on the integral role of estrogens in prostate carcinogenesis (Ellem \& Risbridger 2007, Risbridger et al. 2010). Overall, ER $\alpha$ is low to detect in prostatic epithelial cells where ER $\beta$ is predominantly expressed. $\mathrm{ER} \beta$ expression is highly variable in human tissues depending on disease status (Leav et al. 2001). Recent data from our laboratory show that an ER $\beta$ agonist compound selectively induces apoptosis in castrateresistant $\mathrm{CD}_{133^{+}}$basal cells, providing a rationale for further exploration of the role of ER $\beta$ in prostatic stem cells and in cancer (McPherson et al. 2010).

\section{Conclusions}

Relapse of prostate cancer in patients with advanced disease after ADT occurs because a proportion of cancer cells resist hormone therapy and become castrate resistant. It is possible that these cells are CRCs that we believe should continue to be the focus of intensive research effort. Achieving this goal is hampered by lack of clarity around the identity of the normal prostatic stem cell(s) and the cancer cell(s) of origin. Stem cells exist in both basal and luminal cell populations and are postulated to comprise intermediate cells that possess characteristics of both cell types. Likewise, the cellular origin of cancer can be from basal and/or luminal cells, using mouse models of prostate cancer. Although we continue to search for the identity of specific stem cells types (normal prostatic stem cells, cancer cells of origin, and/or CRCs) that we believe reside in the normal or diseased epithelium, it is entirely possible that 'stemness' is acquired during repair or tumor propagation and should be considered as a dynamic or transient process that evolves due to environmental pressures, rather than an inherent or sustained property of particular cell types. This creates many challenges in stem cell research as changes in environment, which occur in cell culture and animal models, may suppress the stem cell phenotype that is active within the tumor. The development of models that accurately recreate the tumor microenvironment are vital in order to more accurately assess treatment strategies for their ability to destroy stem cells rather than just decrease the overall tumor size. By using this strategy it is hoped that treatments can be developed to rid patients of the tumors cells responsible for disease relapse and to cure them of their disease.

In the absence of agreement on the identities of cancer cells of origin or CRCs, their androgen sensitivity and responsiveness remains equivocal. The contribution of stroma to stem cell differentiation is also rarely considered, although it clearly plays 
an important role in mediating androgen-stimulated paracrine signaling from the stromal microenvironment. The initial hype and hope surrounding CRCs remains, but relies on the identification of these cell populations in localized and advanced disease.

\section{Declaration of interest}

The authors declare that there is no conflict of interest that could be perceived as prejudicing the impartiality of the research reported.

\section{Funding}

This work was supported by the Prostate Cancer Foundation of Australia (PCFA Y01), US Department of Defense (PC073444) and the Australian Research Council (DP0987059).

\section{Author contribution statement}

All authors contributed to the manuscript and figures.

\section{Acknowledgments}

The authors wish to acknowledge Dr Stuart Ellem for assistance with figure preparation.

\section{References}

Abrahamsson PA 1999 Neuroendocrine cells in tumour growth of the prostate. Endocrine-Related Cancer 6 503-519. (doi:10.1677/erc.0.0060503)

Ao M, Franco OE, Park D, Raman D, Williams K \& Hayward SW 2007 Cross-talk between paracrine-acting cytokine and chemokine pathways promotes malignancy in benign human prostatic epithelium. Cancer Research 67 4244-4253. (doi:10.1158/0008-5472.CAN-06-3946)

Asselin-Labat ML, Shackleton M, Stingl J, Vaillant F, Forrest NC, Eaves CJ, Visvader JE \& Lindeman GJ 2006 Steroid hormone receptor status of mouse mammary stem cells. Journal of the National Cancer Institute $\mathbf{9 8}$ 1011-1014. (doi:10.1093/jnci/djj267)

Asselin-Labat ML, Vaillant F, Sheridan JM, Pal B, Wu D, Simpson ER, Yasuda H, Smyth GK, Martin TJ, Lindeman GJ et al. 2010 Control of mammary stem cell function by steroid hormone signalling. Nature 465 798-802. (doi:10. 1038/nature09027)

Birnie R, Bryce SD, Roome C, Dussupt V, Droop A, Lang SH, Berry PA, Hyde CF, Lewis JL, Stower MJ et al. 2008 Gene expression profiling of human prostate cancer stem cells reveals a pro-inflammatory phenotype and the importance of extracellular matrix interactions. Genome Biology 9 R83. (doi:10.1186/gb-2008-9-5-r83)
Bonkhoff H 1996 Role of the basal cells in premalignant changes of the human prostate: a stem cell concept for the development of prostate cancer. European Urology 30 201-205.

Bonkhoff H \& Remberger K 1993 Widespread distribution of nuclear androgen receptors in the basal cell layer of the normal and hyperplastic human prostate. Virchows Archiv. A, Pathological Anatomy and Histopathology 422 35-38. (doi:10.1007/BF01605130)

Bonkhoff H, Stein U \& Remberger K 1994 The proliferative function of basal cells in the normal and hyperplastic human prostate. Prostate 24 114-118. (doi:10.1002/pros. 2990240303)

Bonnet D \& Dick JE 1997 Human acute myeloid leukemia is organized as a hierarchy that originates from a primitive hematopoietic cell. Nature Medicine 3 730-737. (doi:10. 1038/nm0797-730)

Bostwick D \& Dundore P 1997 Normal anatomy and histology. In Biopsy Pathology of the Prostate, 1st edn, pp 1-26. Eds AM Neville, F Walker, CR Taylor \& LS Gottlieb. London, UK: Chapman \& Hall.

Burger PE, Xiong X, Coetzee S, Salm SN, Moscatelli D, Goto K \& Wilson EL 2005 Sca-1 expression identifies stem cells in the proximal region of prostatic ducts with high capacity to reconstitute prostatic tissue. PNAS 102 7180-7185. (doi:10.1073/pnas. 0502761102)

Campbell LL \& Polyak K 2007 Breast tumor heterogeneity: cancer stem cells or clonal evolution? Cell Cycle $\mathbf{6}$ 2332-2338.

Chung LW \& Cunha GR 1983 Stromal-epithelial interactions: II. Regulation of prostatic growth by embryonic urogenital sinus mesenchyme. Prostate 4 503-511. (doi:10.1002/pros.2990040509)

Coffey DS 1992 The molecular biology, endocrinology, and physiology of the prostate and seminal vesicles. In Campbell's Urology, 6th edn, pp 221-301. Eds PC Walsh, AB Retik, TA Stamey \& ED Vaughan. Philadelphia PA, USA: WB Saunders.

Collins AT, Habib FK, Maitland NJ \& Neal DE 2001 Identification and isolation of human prostate epithelial stem cells based on alpha(2)beta(1)-integrin expression. Journal of Cell Science 114 3865-3872.

Collins AT, Berry PA, Hyde C, Stower MJ \& Maitland NJ 2005 Prospective identification of tumorigenic prostate cancer stem cells. Cancer Research 65 10946-10951. (doi:10.1158/0008-5472.CAN-05-2018)

Cunha AR 1994 Role of mesenchymal-epthelial interactions in normal and abnormal development of male urogenital glands. In Ultrastructure of Male Urogenital Glands: Prostate, Seminal Vesicles, Urethral, and Bulbourethral Glands, Eds A Riva, F Testa Riva \& PM Motta. Boston, MA, USA: Kluwer Academic Publishers.

Cunha GR \& Donjacour AA 1989 Mesenchymal-epithelial interactions in the growth and development of the prostate. Cancer Treatment and Research 46 159-175. 
De Marzo AM, Meeker AK, Epstein JI \& Coffey DS 1998 Prostate stem cell compartments: expression of the cell cycle inhibitor p27Kip1 in normal, hyperplastic, and neoplastic cells. American Journal of Pathology 153 911-919.

DeKlerk DP \& Coffey DS 1978 Quantitative determination of prostatic epithelial and stromal hyperplasia by a new technique. Biomorphometrics. Investigative Urology 16 240-245.

Dick JE 2009 Looking ahead in cancer stem cell research. Nature Biotechnology 27 44-46. (doi:10.1038/nbt0109-44)

Donjacour A \& Cunha G 1993 Assessment of prostatic protein secretion in tissue recombinants made of urogenital sinus mesenchyme and urothelium from normal or androgen-insensitive mice. Endocrinology 132 2342-2350. (doi:10.1210/en.132.6.2342)

El-Alfy M, Pelletier G, Hermo LS \& Labrie F 2000 Unique features of the basal cells of human prostate epithelium. Microscopy Research and Technique 51 436-446. (doi:10.1002/1097-0029(20001201)51:5<436::AIDJEMT6 > 3.0.CO;2-T)

Ellem SJ \& Risbridger GP 2007 Treating prostate cancer: a rationale for targeting local oestrogens. Nature Reviews. Cancer 7 621-627. (doi:10.1038/nrc2174)

Ellwood-Yen K, Graeber TG, Wongvipat J, Iruela-Arispe ML, Zhang J, Matusik R, Thomas GV \& Sawyers CL 2003 Myc-driven murine prostate cancer shares molecular features with human prostate tumors. Cancer Cell 4 223-238. (doi:10.1016/S1535-6108(03)00197-1)

Foster CS, Dodson A, Karavana V, Smith PH \& Ke Y 2002 Prostatic stem cells. Journal of Pathology 197 551-565. (doi:10.1002/path.1194)

Goldstein AS, Lawson DA, Cheng D, Sun W, Garraway IP \& Witte ON 2008 Trop2 identifies a subpopulation of murine and human prostate basal cells with stem cell characteristics. PNAS 105 20882-20887. (doi:10.1073/ pnas.0811411106)

Grisanzio C \& Signoretti S 2008 p63 in prostate biology and pathology. Journal of Cellular Biochemistry 103 1354-1368. (doi:10.1002/jcb.21555)

Hanahan D \& Weinberg RA 2000 The hallmarks of cancer. Cell 100 57-70. (doi:10.1016/S0092-8674(00)81683-9)

Hayward SW, Rosen MA \& Cunha GR 1997 Stromalepithelial interactions in the normal and neoplastic prostate. British Journal of Urology 79 (Suppl 2) 18-26.

Heer R, Robson CN, Shenton BK \& Leung HY 2007 The role of androgen in determining differentiation and regulation of androgen receptor expression in the human prostatic epithelium transient amplifying population. Journal of Cellular Physiology 212 572-578. (doi:10.1002/jcp. 21154)

Henshall SM, Quinn DI, Lee CS, Head DR, Golovsky D, Brenner PC, Delprado W, Stricker PD, Grygiel JJ \& Sutherland RL 2001 Altered expression of androgen receptor in the malignant epithelium and adjacent stroma is associated with early relapse in prostate cancer. Cancer Research 61 423-427.
Hudson DL 2004 Epithelial stem cells in human prostate growth and disease. Prostate Cancer and Prostatic Diseases 7 188-194. (doi:10.1038/sj.pcan.4500745)

Humphrey PA 2007 Diagnosis of adenocarcinoma in prostate needle biopsy tissue. Journal of Clinical Pathology 60 35-42. (doi:10.1136/jcp.2005.036442)

Isaacs JT \& Coffey DS 1989 Etiology and disease process of benign prostatic hyperplasia. Prostate. Supplement 2 33-50. (doi:10.1002/pros.2990150506)

Iwata T, Schultz D, Hicks J, Hubbard GK, Mutton LN, Lotan TL, Bethel C, Lotz MT, Yegnasubramanian S, Nelson WG et al. 2010 MYC overexpression induces prostatic intraepithelial neoplasia and loss of Nkx3.1 in mouse luminal epithelial cells. PLoS ONE 5 e9427. (doi:10.1371/ journal.pone.0009427)

Joesting MS, Perrin S, Elenbaas B, Fawell SE, Rubin JS, Franco OE, Hayward SW, Cunha GR \& Marker PC 2005 Identification of SFRP1 as a candidate mediator of stromal-to-epithelial signaling in prostate cancer. Cancer Research 65 10423-10430. (doi:10.1158/0008-5472. CAN-05-0824)

Kelly PN, Dakic A, Adams JM, Nutt SL \& Strasser A 2007 Tumor growth need not be driven by rare cancer stem cells. Science 317 337. (doi:10.1126/science.1142596)

Kurita T, Medina RT, Mills AA \& Cunha GR 2004 Role of p63 and basal cells in the prostate. Development 131 4955-4964. (doi:10.1242/dev.01384)

Kyprianou N \& Isaacs JT 1988 Identification of a cellular receptor for transforming growth factor-beta in rat ventral prostate and its negative regulation by androgens. Endocrinology 123 2124-2131. (doi:10.1210/endo123-4-2124)

Lawson DA, Xin L, Lukacs RU, Cheng D \& Witte ON 2007 Isolation and functional characterization of murine prostate stem cells. PNAS 104 181-186. (doi:10.1073/ pnas.0609684104)

Lawson DA, Zong Y, Memarzadeh S, Xin L, Huang J \& Witte ON 2010 Basal epithelial stem cells are efficient targets for prostate cancer initiation. PNAS 107 2610-2615. (doi:10.1073/pnas.0913873107)

Leav I, Lau KM, Adams JY, McNeal JE, Taplin ME, Wang J, Singh H \& Ho SM 2001 Comparative studies of the estrogen receptors beta and alpha and the androgen receptor in normal human prostate glands, dysplasia, and in primary and metastatic carcinoma. American Journal of Pathology 159 79-92.

van Leenders GJ \& Schalken JA 2001 Stem cell differentiation within the human prostate epithelium: implications for prostate carcinogenesis. BJU International 88 (Suppl 2) 35-42 (discussion 49-50). (doi:10.1046/j. 1464-410X.2001.00117.x)

Leong KG, Wang BE, Johnson L \& Gao WQ 2008 Generation of a prostate from a single adult stem cell. Nature 456 804-808. (doi:10.1038/nature07427)

Lim E, Vaillant F, Wu D, Forrest NC, Pal B, Hart AH, Asselin-Labat ML, Gyorki DE, Ward T, Partanen A et al. 2009 Aberrant luminal progenitors as the candidate 
target population for basal tumor development in BRCA1 mutation carriers. Nature Medicine 15 907-913. (doi:10.1038/nm.2000)

Liu AY, True LD, LaTray L, Nelson PS, Ellis WJ, Vessella RL, Lange PH, Hood L \& van den Engh G 1997 Cell-cell interaction in prostate gene regulation and cytodifferentiation. PNAS 94 10705-10710. (doi:10.1073/pnas.94.20.10705)

Locke JA, Guns ES, Lubik AA, Adomat HH, Hendy SC, Wood CA, Ettinger SL, Gleave ME \& Nelson CC 2008 Androgen levels increase by intratumoral de novo steroidogenesis during progression of castration-resistant prostate cancer. Cancer Research 68 6407-6415. (doi:10. 1158/0008-5472.CAN-07-5997)

Lukacs RU, Goldstein AS, Lawson DA, Cheng D \& Witte ON 2010 Isolation, cultivation and characterization of adult murine prostate stem cells. Nature Protocols 5 702-713. (doi:10.1038/nprot.2010.11)

Ma X, Ziel-van der Made AC, Autar B, van der Korput HA, Vermeij M, van Duijn P, Cleutjens KB, de Krijger R, Krimpenfort P, Berns A et al. 2005 Targeted biallelic inactivation of Pten in the mouse prostate leads to prostate cancer accompanied by increased epithelial cell proliferation but not by reduced apoptosis. Cancer Research 65 5730-5739. (doi:10.1158/0008-5472. CAN-04-4519)

McNeal JE 1981 Normal and pathologic anatomy of prostate. Urology 17 11-16.

McNeal JE 1988 Normal histology of the prostate. American Journal of Surgical Pathology 12 619-633. (doi:10.1097/ 00000478-198808000-00003)

McPherson SJ, Hussain S, Balanathan P, Hedwards S, Niranjan B, Grant M, Chandrasiri UP, Toivanen R, Wang Y, Taylor RA et al. 2010 Estrogen receptor beta activated apoptosis in benign hyperplasia and cancer of the prostate is androgen-independent and TNF-A mediated. PNAS 107 3123-3128. (doi:10.1073/pnas. 0905524107)

Montpetit M, Abrahams P, Clark AF \& Tenniswood M 1988 Androgen-independent epithelial cells of the rat ventral prostate. Prostate 12 13-28. (doi:10.1002/pros. 2990120104)

Mulholland DJ, Xin L, Morim A, Lawson D, Witte O \& Wu H 2009 Lin-Sca-1 + CD49f high stem/progenitors are tumor-initiating cells in the Pten-null prostate cancer model. Cancer Research 69 8555-8562. (doi:10.1158/ 0008-5472.CAN-08-4673)

O'Brien CA, Pollett A, Gallinger S \& Dick JE 2007 A human colon cancer cell capable of initiating tumour growth in immunodeficient mice. Nature 445 106-110. (doi:10. 1038/nature05372)

Olumi AF, Grossfeld GD, Hayward SW, Carroll PR, Tlsty TD \& Cunha GR 1999 Carcinoma-associated fibroblasts direct tumor progression of initiated human prostatic epithelium. Cancer Research 59 5002-5011.
Penson D \& Chan J 2007 Urological diseases in America project: Prostate cancer. Journal of Urology 177 2020-2029. (doi:10.1016/j.juro.2007.01.121)

Potten CS \& Loeffler M 1990 Stem cells: attributes, cycles, spirals, pitfalls and uncertainties. Lessons for and from the crypt. Development 110 1001-1020.

Quintana E, Shackleton M, Sabel MS, Fullen DR, Johnson TM \& Morrison SJ 2008 Efficient tumour formation by single human melanoma cells. Nature 456 593-598. (doi:10.1038/nature07567)

Reya T, Morrison SJ, Clarke MF \& Weissman IL 2001 Stem cells, cancer, and cancer stem cells. Nature 414 105-111. (doi:10.1038/35102167)

Ricciardelli C, Choong CS, Buchanan G, Vivekanandan S, Neufing P, Stahl J, Marshall VR, Horsfall DJ \& Tilley WD 2005 Androgen receptor levels in prostate cancer epithelial and peritumoral stromal cells identify nonorgan confined disease. Prostate 63 19-28. (doi:10.1002/ pros.20154)

Richardson GD, Robson CN, Lang SH, Neal DE, Maitland NJ \& Collins AT 2004 CD133, a novel marker for human prostatic epithelial stem cells. Journal of Cell Science 117 3539-3545. (doi:10.1242/jcs.01222)

Risbridger GP, Davis ID, Birrell SN \& Tilley W 2010 Breast and prostate cancer: more similar than different. Nature Reviews. Cancer 10 205-212. (doi:10.1038/ nrc2795)

Schatton T, Murphy GF, Frank NY, Yamaura K, WaagaGasser AM, Gasser M, Zhan Q, Jordan S, Duncan LM, Weishaupt C et al. 2008 Identification of cells initiating human melanomas. Nature 451 345-349. (doi:10.1038/ nature06489)

Scher HI, Buchanan G, Gerald W, Butler LM \& Tilley WD 2004 Targeting the androgen receptor: improving outcomes for castration-resistant prostate cancer. Endocrine-Related Cancer 11 459-476. (doi:10.1677/ erc.1.00525)

Shackleton M, Vaillant F, Simpson KJ, Stingl J, Smyth GK, Asselin-Labat ML, Wu L, Lindeman GJ \& Visvader JE 2006 Generation of a functional mammary gland from a single stem cell. Nature 439 84-88. (doi:10.1038/nature04372)

Shackleton M, Quintana E, Fearon ER \& Morrison SJ 2009 Heterogeneity in cancer: cancer stem cells versus clonal evolution. Cell 138 822-829. (doi:10.1016/j.cell. 2009.08.017)

Shepherd CJ, Rizzo S, Ledaki I, Davies M, Brewer D, Attard G, de Bono J \& Hudson DL 2008 Expression profiling of $\mathrm{CD} 133+$ and CD133 - epithelial cells from human prostate. Prostate 68 1007-1024. (doi:10.1002/pros.20765)

Signoretti S \& Loda M 2007 Prostate stem cells: from development to cancer. Seminars in Cancer Biology 17 219-224. (doi:10.1016/j.semcancer.2006.04.004)

Signoretti S, Waltregny D, Dilks J, Isaac B, Lin D, Garraway L, Yang A, Montironi R, McKeon F \& Loda M 2000 p63 is a prostate basal cell marker and is required for prostate development. American Journal of Pathology 157 1769-1775. 
Takeda H, Suematsu N \& Mizuno T 1990 Transcription of prostatic steroid binding protein (PSBP) gene is induced by epithelial-mesenchymal interaction. Development 110 273-281.

Taylor RA \& Risbridger GP 2008 Prostatic tumor stroma: a key player in cancer progression. Current Cancer Drug Targets 8 490-497. (doi:10.2174/156800908785699351)

Taylor RA, Wang H, Wilkinson SE, Richards MG, Britt KL, Vaillant F, Lindeman GJ, Visvader JE, Cunha GR, St John J et al. 2009 Lineage enforcement by inductive mesenchyme on adult epithelial stem cells across developmental germ layers. Stem Cells 27 3032-3042. (doi:10.1002/stem.244)

Tsujimura A, Fujita K, Komori K, Takao T, Miyagawa Y, Takada S, Matsumiya K, Nonomur N \& Okuyama A 2007 Prostatic stem cell marker identified by cDNA microarray in mouse. Journal of Urology 178 686-691. (doi:10.1016/ j.juro.2007.03.092)

Uzgare AR, Xu Y \& Isaacs JT 2004 In vitro culturing and characteristics of transit amplifying epithelial cells from human prostate tissue. Journal of Cellular Biochemistry 91 196-205. (doi:10.1002/jcb.10764)

Vander Griend DJ, Karthaus WL, Dalrymple S, Meeker A, DeMarzo AM \& Isaacs JT 2008 The role of CD133 in normal human prostate stem cells and malignant cancerinitiating cells. Cancer Research 68 9703-9711. (doi:10. 1158/0008-5472.CAN-08-3084)

Verhagen AP, Aalders TW, Ramaekers FC, Debruyne FM \& Schalken JA 1988 Differential expression of keratins in the basal and luminal compartments of rat prostatic epithelium during degeneration and regeneration. Prostate 13 25-38. (doi:10.1002/pros.2990130104)

Visvader JE 2009 Keeping abreast of the mammary epithelial hierarchy and breast tumorigenesis. Genes and Development 23 2563-2577. (doi:10.1101/gad.1849509)
Wang Y, Hayward S, Cao M, Thayer K \& Cunha G 2001 Cell differentiation lineage in the prostate. Differentiation 68 270-279. (doi:10.1046/j.1432-0436.2001. 680414.x)

Wang S, Garcia AJ, Wu M, Lawson DA, Witte ON \& Wu H 2006 Pten deletion leads to the expansion of a prostatic stem/progenitor cell subpopulation and tumor initiation. PNAS 103 1480-1485. (doi:10.1073/pnas. 0510652103)

Wang X, Kruithof-de Julio M, Economides KD, Walker D, Yu H, Halili MV, Hu YP, Price SM, Abate-Shen C \& Shen MM 2009 A luminal epithelial stem cell that is a cell of origin for prostate cancer. Nature 461 495-500. (doi:10.1038/nature08361)

Watt FM \& Hogan BL 2000 Out of Eden: stem cells and their niches. Science 287 1427-1430. (doi:10.1126/science. 287.5457.1427)

Wicha MS, Liu S \& Dontu G 2006 Cancer stem cells: an old idea - a paradigm shift. Cancer Research 66 1883-1890 (discussion 1895-1886). (doi:10.1158/0008-5472. CAN-05-3153)

Wikstrom P, Marusic J, Stattin P \& Bergh A 2009 Low stroma androgen receptor level in normal and tumor prostate tissue is related to poor outcome in prostate cancer patients. Prostate 69 799-809. (doi:10.1002/pros. 20927)

Xin L, Lawson DA \& Witte ON 2005 The Sca-1 cell surface marker enriches for a prostate-regenerating cell subpopulation that can initiate prostate tumorigenesis. PNAS 102 6942-6947. (doi:10.1073/pnas. 0502320102)

Yao M, Taylor RA, Richards MG, Sved P, Wong J, Eisinger D, Xie C, Salomon R, Risbridger GP \& Dong Q 2010 Prostate-regenerating capacity of cultured human adult prostate epithelial cells. Cells, Tissues, Organs 191 203-212. (doi:10.1159/000240244) 